\title{
MÚLTIPLAS PERSPECTIVAS DA CARTOGRAFIA NA FORMAÇÃO INICIAL EM GEOGRAFIA
}

\author{
Ismail Barra Nova de Melo ${ }^{1}$
}

Resumo: A Cartografia tem um papel importante a cumprir no curso de licenciatura em Geografia, principalmente como linguagem. O presente artigo tem como objetivo apresentar algumas discussões relacionadas a Cartografia que consideramos pertinente na formação do professor de Geografia. Esta é uma pesquisa bibliográfica que busca um diálogo com autores que discutem diferentes posições para a Cartografia. Conclui-se que a Cartografia atualmente, diferente daquela posição vinculada ao dominador, pode: a) permear o ensino da Geografia no ensino básico; b) ajudar no entendimento do processo de construção histórica do espaço geográfico; c) contribuir na formação do cidadão; e d) ser um instrumento de luta de diferentes grupos da sociedade civil.

Palavras-Chave: Cartografia Escolar; Formação de Professor; Geografia.

\section{MULTIPLE PERSPECTIVES ON CARTOGRAPHY IN THE INITIAL TEACHER-TRAINING IN GEOGRAPHY}

\begin{abstract}
Cartography has an important role to play in the Geography degree, mainly as a language. This article aims to present some discussions related to cartography, whichwe consider relevant in Geography teacher-training. This is a bibliographical research that looking for a dialogue with the different views in Cartography. So, we believe this can - contrary to the prevalent position: a) permeate the teaching of Geography; b) help in understanding the process of historical construction of geographic space; c) contribute to citizen formation; and d) be an instrument to be use in conflicts of different social groups.

Keywords: School Cartography, Teacher-training Bachelor, Geography
\end{abstract}

\section{INTRODUÇÃO}

Este artigo é o resultado da mesa realizada no I Encontro Lívia de Oliveira, realizado em agosto de 2017 na UNESP de Rio Claro-SP, cujo desafio foi falar sobre as múltiplas perspectivas da Cartografia na formação do professor de Geografia, por isso, será apresentado um panorama de temas que podem permear o curso de Geografia, sem a pretensão de esgotar cada eixo aqui elencando. Outra ressalva

\footnotetext{
${ }^{1}$ Docente associado da Universidade Federal de São Carlos - UFSCAR. E-mail: ismail@ufscar.br
} 
que se faz é que não se pretende esgotar todas as possibilidades de temas e procedimentos, logo, alguns temas e procedimentos podem ter ficado de fora.

Pensar na formação inicial de professores de Geografia com múltiplas perspectivas, tendo foco a Cartografia Escolar, é um desafio enorme, no entanto, esta preocupação deve permear as disciplinas de Cartografia na licenciatura em Geografia. Dentre as múltiplas perspectivas, destaco algumas que considero importantes, no entanto, não significa que são as únicas, porém, me fazem refletir de modo particular, que são: o saber Cartográfico socialmente produzido; as Geotecnologias, o saber Cartográfico a ser ensinado e a Cartografia Escolar.

\section{O SABER CARTOGRÁFICO SOCIALMENTE PRODUZIDO}

Não se tem o objetivo aqui fazer um resgate da produção social do mapa ao longo da humanidade, no entanto, frisar alguns pontos que não podem ser ignorados na formação inicial do professor de Geografia. Não restam dúvidas alguma de que a História dos mapas é muito rica e valiosa na compreensão do domínio que o Homem teve do seu território. Rica também é a diversidade da representação dos territórios das diferentes sociedades ao longo da humanidade, logo, não se pode ficar preso apenas a uma História da Cartografia Ocidental, ou seja, centrada na Europa, principalmente.

Ao contrário, deve-se buscar nesse quesito demonstrar os mapas das diferentes sociedades de diferentes lugares, independentemente do seu nível de desenvolvimento econômico e militar. Isto significa que mapas de outras sociedades devem ser retratados, ou seja, da América, da África, da Oceania e da Ásia. Pois a elaboração de mapas é anterior a escrita e o mesmo pode ser encontrado em praticamente em todos os povos (RAISZ, 1985). Neste sentido, os mapas pertencem a um determinado contexto que:

[...] pode ser definido como as circunstâncias nas quais os mapas foram elaborados e utilizados. Numa analogia com a "situação de fala" num estudo lingüístico, isto implica reconstruir os quadros físicos e sociais que determinaram a produção e o consumo dos mapas, os acontecimentos que conduziram a essas ações, a identidade dos produtores e dos usuários dos mapas, e a maneira como eles percebiam $o$ ato de produzir e utilizar os mapas num mundo socialmente construído (HARLEY, 2009, p. 4).

Além deste enfoque em diferentes locais, deve-se também trazer para a discussão os mapas de diferentes atores, quer dizer, não ficar centrado apenas nos mapas oficiais ou da cartografia científica, mas também os diferentes pontos de vista, ou seja, ler "[...] e fazer mapas - oficiais ou subversivos, imaginários ou reais, materiais ou digitais, do bairro ou do mundo inteiro - são atividades imprescindíveis para transformar a educação cartográfica em um projeto pluralista" (SEEMANN, 2012, p. 167).

Pensar uma cartografia pluralista não se pode deixar de referenciar os mapas mentais, pois os mesmos são produções dos sujeitos "[...] como integrantes de uma realidade, articulando o real e o imaginário, o cotidiano à fantasia nas 
representações espaciais, refletindo ainda uma ideologia referendando uma visão de mundo" (KOZEL, 2005, p. 148).

Outro ponto importante neste resgate histórico da produção social do saber cartográfico é a compreensão do mapa em seus diferentes contextos, quer dizer, mostrar que o mapa das sociedades antigas, mesmo sem as técnicas atuais, tinha os mesmos objetivos dos dias presentes, ou seja, conhecer o seu território. Esta postura expande o conceito de mapa para além dos aspectos euclidianos, ou seja, as pinturas rupestres e outras representações podem ser consideradas mapas, mesmo sem escala, projeção e legenda, pois:

[...] figurações espaciais dos povos dominados, subjugados ou até mesmo exterminados foram durante longa data consideradas inferiores aos mapas produzidos sob a égide do rigor científico. É neste contexto que devemos entender a expressão pré-mapas [...] (KATUTA, 2005, p. 41, grifo do autor).

Discutir a função do mapa em cada contexto histórico também não pode ficar de fora. Nesta ótica é importante destacar que cada mapa cumpre um determinado objetivo, logo, o mapa não é neutro, pois carrega em si os filtros e as perspectivas do seu autor ou de quem o encomendou. Esta é a oportunidade para se discutir a comunicação cartográfica, ou seja, os elementos que a envolve, desta forma, compreender que o mapa é resultado de um processo intencional, logo, é possível ter diferentes mapas para um mesmo tema e local com objetivos distintos. Pois, segundo Simielli (1986), a comunicação cartográfica é o meio pelo qual o Cartógrafo usa par enviar a sua mensagem codificada da realidade ao usuário através da linguagem cartográfica.

O saber cartográfico acadêmico é outra discussão que deve permear a formação do professor de Geografia. Neste item devem ser trabalhados os diferentes temas ou conceitos básicos da Cartografia. Porém, é preciso atentar para não incorrer no equívoco de trabalhar a forma sem conteúdo, ou seja, isolar a Cartografia de um lado e a Geografia de outro. Esta é oportunidade de se pensar a Cartografia Geográfica (GIRARDI, 2003; GIRARDI, 2007; GIRARDI, 2011). Que permite, entre outras questões, discutir os conceitos chave de Cartografia através de situações geográficas, quer dizer, dispor de raciocínios geográficos por meio das técnicas cartográficas (GIRARDI, 2003).

Para que a Cartografia não fique restrita a um discurso oficial ou apenas daqueles que venceram, faz-se necessário a sua discussão e impacto na presença de movimentos sociais ou comunidades que resistem as diferentes pressões, neste caso, o mapeamento participativo, com destaque para a Cartografia Social, tem desempenhado um papel singular na representação das reivindicações de populações locais a partir das suas perspectivas, quer dizer, elaboração de mapas a partir das suas necessidades. Estes mapas servem, além do processo em si que já é algo impressionante, como instrumento de reivindicações e de resistência. A Cartografia Social está cada vez mais permeando a luta das diferentes resistências na sociedade brasileira, logo, o espaço pode ser representado por diferentes perspectivas:

[...] em que os mapeamentos são eles próprios objetos da ação política. E se ação política diz especificamente respeito à divisão do 
mundo social, podemos considerar que na política dos mapeamentos estabelece-se uma disputa entre distintas representações do espaço, ou seja, uma disputa cartográfica que articula-se às próprias disputas territoriais (ACSELRAD; COLI, 2008, p. 14).

Esta vertente do mapeamento participativo tem se mostrado muito rica e tem apresentado outro olhar para as representações, cada qual com as suas especificidades, são experiências únicas retratadas pela etnocartografia que "[...] lida com a produção de mapas onde a cultura e os elementos históricos são muito relevantes na caracterização de uma cultura específica; além disso, estuda situações em que o conhecimento tradicional é uma parte relevante do processo de mapeamento" (ALMEIDA; ALMEIDA, 2014, p. 888).

Nesta direção de atendimento de representações para outros públicos, a Cartografia Tátil, também é outra contribuição importante para situações do ensino e aprendizagem em Geografia inclusiva, como também para facilitar o entendimento do espaço geográfico de forma mais lúdica. $O$ atendimento específico de um grupo,

[...] tais como pessoas com deficiência visual, dependem de uma cartografia não convencional, voltada a realidades diversas, onde o ensino e a aprendizagem de Geografia têm objetivos diversos. Esses grupos de usuários requerem treinamento específico e disponibilidade de mapas com características especiais em termos de concepção e produção (ALMEIDA, 2007, p. 113).

Mesmo que não tenha o objetivo de atender a uma população específica, como a Cartografia Tátil, a Cartografia História é outro enfoque interessante, pois proporciona o entendimento da construção do espaço geográfico em diferentes contextos históricos, desta forma, é possível identificar num recorte espacial e temporal as permanências e mudanças ocorridas. Além deste objetivo é possível ainda a elaboração de mapas conjecturais a partir de informações obtidas de um determinado local, logo, a confecção de mapas nesta perspectiva tem contribuído para o preenchimento de algumas lacunas de determinados territórios.

A Cartografia História é muito rica nos estudos dos mapas do passado no qual é possível identificar as técnicas "[...] cartográficas empregadas no mapa histórico, cuja multiplicidade de linguagens gráficas adotadas tem sido objeto de análise da História, da Geografia, da Arquitetura, da Sociologia, da Arqueologia, entre outras áreas afins" (CASTRO, 2017, p. 39).

A Cartografia História pode contar com as tecnologias atuais no processo de elaboração, principalmente, dos mapas conjecturais. As Geotecnologias, próximo item que será abordado, são ferramentas importantes neste auxílio de aproximação entre passado e presente.

\section{AS GEOTECNOLOGIAS}

Estudos Geográficos, Rio Claro, 16(1): 268-279, jan./jun. 2018 (ISSN 1678-698X)

http://www.periodicos.rc.biblioteca.unesp.br/index.php/estgeo 
As geotecnologias, entendidas como "[...] o conjunto de tecnologias para coleta, processamento, análise e oferta de informações com referência geográfica" (ROSA, 2005, p. 81), também não podem ficar de fora desta discussão. Entram aqui os programas computacionais para a confecção de mapas, ou seja, os Sistemas de Informações Geográficas, associados com o sensoriamento remoto, bem como outros dispositivos computacionais que englobam as novas tecnologias da Informação e Comunicação (TICs).

Neste quesito em particular é importante não perder de vista que as Geotecnologias "[...] são um meio poderoso para atingir os objetivos da Geografia Aplicada" (FLORENZANO, 2005, p. 28). No nosso caso no processo de ensino e aprendizagem da Geografia, quer dizer, aprender a elaboração de mapas, manualmente ou com o auxílio do computador, deve ser um recurso que auxilia o futuro professor na contextualização do território que queira ensinar a partir da sua perspectiva ou para elaborar mapas temáticos municipais, que normalmente não são encontrados com tanta facilidade.

É importante destacar que atualmente existem inúmeros programas gratuitos para a confecção de mapas, como o Spring, o Philcarto, o QGis, etc. Porém, para o que o futuro professor não se torne um apertador de botões é preciso que o mesmo entenda os fundamentos básicos da Cartografia Temática e que possa, na ausência de programas computacionais, elaborar mapas manualmente com os princípios da semiologia gráfica, pois muitas escolas não dispõem de computadores disponíveis, desta forma, o professor não ficará refém dos materiais didáticos ou da falta de computadores. Cabe ressaltar que existem programas elaborados para o ensino da Geografia, como o GEODEN (DI MAIO, 2004; DI MAIO, 2007).

Além dos programas gratuitos para a confecção de mapas existem também os programas que disponibilizam mapas e imagens de satélites que são muito difundidos na internet e seu uso tem sido pesquisado no ensino de Geografia, como o Google Earth (ROSA, SANTO JÚNIOR, LAHM, 2007; GONÇALVES, et al 2007, SILVA, CHAVES, 2011; FREISLEBEN, KAERCHER, 2014); e o Google Maps (SILVA, CHAVES, 2011; FREISLEBEN, KAERCHER, 2014), que auxiliam significativamente a compreensão do espaço geográfico que se quer analisar. Ressalta-se que o Google Earth, de forma amigável, permite uma boa interação entre usuário e mapa na qual é possível elaborar caminhos, polígonos e pontos, sobreposição de imagens, visualizar imagens de satélites históricas, realizar voos panorâmicos, inserir outros mapas, etc. O Google Maps, com menos recursos, também proporciona uma boa interação com o usuário.

Novamente aqui é interessante não só apresentar os potenciais destes programas como também trazer para a discussão das publicações de autores que fizeram usos destes programas e os resultados alcançados, quer dizer, quais aproximações são possíveis de serem feitas entre aquilo que já é de conhecimento de um grande público e o seu uso como recurso no processo de ensino e aprendizagem da Geografia. Estes programas, assim como os de elaboração de mapas, permitem grandes inovações no ensino e aprendizagem da Geografia, principalmente na inserção de conteúdos locais.

Existe também o Sistema IBGE de Recuperação Automática - SIDRA. Tratase um banco de dados geográficos com diferentes temáticas. Nesse sistema é 
possível acessar os dados por meio de filtros de temas, de datas, de base territorial, etc., assim, é possível ao final ter disponível os dados em forma de tabelas ou mapas. Os mapas e tabelas podem ser baixados pelo usuário ou enviados para o seu e-mail. Trata-se de um excelente banco de dados no qual o usuário pode elaborar a sua tabela e o seu mapa, tornando-se um instrumento muito rico para as discussões na formação do licenciado em Geografia (IBGE, 2017).

Cabe ressaltar que a proposição do uso destes programas computacionais e do sistema disponíveis na internet faça parte do cotidiano da prática pedagógica do professor, que dizer, a própria elaboração dos mapas ou tabelas é o momento de aprendizagem dos temas geográficos, não se espera, portanto, que o professor leve os mapas prontos aos seus alunos. É oportuno na discussão das Geotecnologias inserir o debate referente a visualização cartográfica (MACEACHREN, TAYLOR, 1994; RAMOS, 2005). A Visualização deve ser contextualizada nas mudanças dos mapas impressos para os mapas digitais e interativos, principalmente com a popularização da informática e o maior acesso a internet.

Nesse contexto de interatividade e conectividade, novos termos foram surgindo, como a cibercultura ou cultura digital, que é a "[...] relação diária que estabelecemos com as tecnologias atuais" (CANTO, ALMEIDA, 2011, p. 147). A elaboração de mapas na internet, individual ou em cooperação com outras pessoas, ganhou novas dimensões, principalmente com a remixagem:

O caráter remix da cibercultura está particularmente ligado a atividades que dependem de uma forma específica de tecnologia que encontramos no ciberespaço, as tecnologias que estimulam o compartilhamento e a apropriação fácil dos dados, linguagens e dispositivos digitais, possibilitando, assim, que novos objetos e informações sejam criados a partir de elementos preexistentes (CANTO, ALMEIDA, 2011, p. 149).

Diante deste novo universo proporcionado pela tecnologia e possibilidades de novos mapeamentos é que temos que repensar a prática pedagógica centrada apenas no livro didático ou materiais de apoio. O próximo tópico se propõe a discutir o saber Cartográfico a ser ensinado, quer dizer, aquele que está na esfera intermediária entre o saber cartográfico acadêmico e o ensinado.

\section{SABER CARTOGRÁFICO A SER ENSINADO}

Outra perspectiva que julgo ser importante na formação do professor é referente ao saber cartográfico a ser ensinado, principalmente por inserir nesta discussão os responsáveis pelo sistema de ensino (MELO, 2007). Aqui é importante a discussão dos Parâmetros Curriculares Nacionais e dos livros didáticos.

A discussão deve ser pautada no enfoque que estes materiais didáticos deram a Cartografia e sua compreensão, por exemplo, os PCNs, apesar do avanço dado ao tema, cometeu o mesmo erro de outros materiais, ou seja, concentrou num único tópico (ALMEIDA, 2001).

Isso demostra a concepção da Cartografia como fim e não como meio. A diferença básica é que ao se propor a Cartografia como fim tem-se a preocupação de trazer a discussão de alguns conceitos de forma isolada e fragmentada, ou seja, 
torna-se um conteúdo. Por outro lado, pensar a Cartografia permeando toda a escolaridade é ter a concepção de linguagem, ou seja, não há separação entre forma e conteúdo, logo, deve-se pensar nos conceitos cartográficos básicos, mas com o intuito de se chegar ao conceito de mapa e facilitar sua leitura e interpretação (MELO, 2014).

Os livros didáticos de Geografia quando não concentram a Cartografia num único capítulo, tratam os mapas como ilustração, ou seja, subutilizam o mapa no processo de ensino e aprendizagem da Geografia. Por isso, é importante que o professor de Geografia possa produzir seu próprio mapa ou outro material, desde que se tenha oferecido esta oportunidade na sua formação inicial, caso contrário, corre-se o risco deste profissional ficar refém do livro didático ou do currículo (SPÓSITO, 2002).

Cabe ressaltar que os conteúdos cartográficos dos livros didáticos não são exclusivamente adaptações do saber cartográfico cientifico, pois numa pesquisa realizada nos livros didáticos de 1824 a 1936 feita por Boligian e Almeida (2011) mostra que:

[...] é possível entender que boa parte do conjunto de conhecimentos geográficos e, mais especificamente, dos conhecimentos cartográficos prescritos nos materiais didáticos nacionais não possui suas origens em um saber sistematizado na academia. Verificamos que suas origens estão apoiadas em um tipo de saber erudito clássico, baseado no espírito das humanidades, os quais formaram o alicerce do ensino secundário em nosso país, antes da fundação das primeiras universidades (BOLIGIAN, ALMEIDA, 2011, p. 88, grifo dos autores).

De acordo com Boligian e Almeida (2011) boa parte dos conteúdos cartográficos, vinculados ao conhecimento geográfico clássico, existem ainda hoje nas escolas. Isso é interessante pois nos remete a pensar a respeito dos referenciais, quer dizer, há outras legitimações para o saber escolar para além do saber científico:

Esses conteúdos explícitos, assim como o método de ensino estabelecido historicamente pelos professores-autores de materiais didáticos, demostram uma produção cultural distinta, na qual verificamos que a Geografia escolar surge não como uma vulgarização ou uma adaptação de conhecimentos geográficos científicos, mas como uma forma de conhecimentos particular e original da instituição escolar e para a instituição escolar (BOLIGIAN, ALMEIDA, 2011, p. 89, grifo dos autores).

Diante desta colocação dos autores fica claro que o saber cartográfico ensinado não é pura e simplesmente um produto da transposição didática, teoria proposta por Chevallard (1991). O conteúdo de ensino pode ter outras legitimações, como as práticas sociais (ARSAC, 1992). 
Por último, mas não menos importante, cabe frisar que, conforme Simielli (2003), a reconstrução do saber geográfico pode ser feita em quatro níveis, que são: dos programas, do professor, da lição e do aluno.

No próximo item discutiremos a Cartografia Escolar e seu papel na formação do licenciado em Geografia.

\section{CARTOGRAFIA ESCOLAR}

A Cartografia Escolar não pode ficar de fora da formação do professor em Geografia, ao contrário, deve permear todos os momentos que se discute a Cartografia no curso. É oportuno trazer à tona a pesquisa pioneira da professora Lívia de Oliveira realizada em 1977 e suas preocupações com o problema didático do mapa, enfatizando o ensino do mapa, sem deixar de lado o ensino pelo mapa, bem como a preocupação com a adequação do mapa para cada faixa etária, ou seja, com o desenvolvimento cognitivo da criança, por isso, destaca se as primeiras relações espaciais são as topológicas, logo, os primeiros mapas para as crianças também deveriam ser os topológicos e não os euclidianos (OLIVEIRA, 1977, OLIVEIRA, 2007).

Foram necessários dezoito anos desde as inquietações da professora Lívia de Oliveira (1977) para a realização do I Colóquio de Cartografia para Crianças (Nome ampliado em 2001 para escolares, IV Colóquio) em 1995 na cidade de Rio Claro-SP (MELO, 2007). A partir deste primeiro evento os colóquios não pararam mais de ocorrer, ampliando de forma significativa as temáticas, as participações e as inquietações. Pode-se dizer que a Cartografia Escolar, em termo de pesquisas, avançou nos últimos anos e se encontra consolidada enquanto linha de pesquisa. Apesar dos avanços, ainda há muito que se pesquisar em Cartografia Escolar.

As questões teóricas e metodológicas discutidas em várias publicações científicas, disponíveis em diferentes formatos, também devem permear a formação do licenciando em Geografia. Destaco aqui alguns livros que trazem coletâneas de capítulos de diferentes autores com vários assuntos relacionados com a Cartografia Escolar: "A Aventura Cartográfica: perspectivas, pesquisas e reflexões sobre a Cartografia Humana", organizado por Jör Seemann (2005); "Cartografia Escolar", organizado por Rosângela Doin de Almeida (2007); "Novos rumos da cartografia escolar: currículo, linguagem e tecnologia", organizado por Rosângela Doin de Almeida (2011) e "Ensino de Geografia em debate", organizado por Diego Corrêa Maia (2014). Estas obras citadas apenas exemplificam alguns referenciais, logo, existem muito mais autores que discutem a Cartografia e Ensino.

A discussão da Cartografia e Ensino, além dos aspectos teóricometodológicos, deve também privilegiar momentos de práticas dos futuros professores. Daqui em diante retrato um pouco da minha experiência na Cartografia Escolar no ensino superior por meio de projetos.

Cada início de semestre é proposto aos licenciandos que formem grupos de trabalhos e, com base nos conhecimentos cartográficos discutidos nos semestres anteriores, escolham uma forma de representação espacial associado com um problema geográfico, desta forma, busca-se por meio de um projeto o 
desenvolvimento de um tema da Geografia que será trabalhado por meio de uma representação cartográfica (MELO, 2014).

Ao longo de um semestre os licenciandos se reúnem, com orientação, com o objetivo de elaborar um projeto de Cartografia Escolar. Este projeto deve conter um tema geográfico, ou seja, um problema que se quer analisar no espaço geográfico. Definição de uma série, podendo ser do ensino fundamental II, do ensino médio ou de outras modalidades. Escolha de meios para representar o tema, que pode ser: uso da maquete, mapas temáticos, Google Earth, Google Maps, Carta Imagem, Sensoriamento Remoto, uso de bússola, mapas murais, mapa tátil, etc. O próximo passo é a elaboração de um roteiro de procedimentos metodológicos de como as ações vão ocorrer no ambiente escolar (MELO, 2014).

A definição da escolha da série se dá em relação ao tema que foi definido, quer dizer, há uma conciliação entre o tema e a série em que se trabalha determinado assunto. A escola é definida a partir de um diálogo entre os licenciandos e os professores de Geografia. Neste caso é preciso deixar claro que o professor responsável pela sala do ensino básico também é convidado a participar efetivamente do projeto. As vezes, é preciso ajuda da universidade na aproximação entre licenciando e professor do ensino básico (MELO, 2014).

Antes do desenvolvimento da prática na escola é discutido com cada grupo os conceitos chave, os procedimentos adotados, os materiais necessários para a prática, o número de aulas, os recursos disponíveis na escola, entre outras questões. Pode-se, a depender do objetivo, realizar um diagnóstico junto aos alunos para se ter um parâmetro do antes e depois da prática pedagógica (MELO, 2014).

A inserção do licenciando na prática da Cartografia Escolar no ambiente escolar é uma iniciativa interessante na qual é possível aliar teoria com a prática, bem como sua inserção nas condições reais do seu futuro ambiente de trabalho. Muitos projetos que previam usos de diferentes recursos nas escolas são modificados a partir da visita a escola a sua real infraestrutura, desafiando o licenciando a buscar alternativas para o seu projeto.

A experiência de trabalhos práticos em grupo de licenciando na escola tem se mostrado proveitosa, pois não diz respeito apenas de um estudo teórico metodológico que se deve alcançar em cada projeto, mas também as percepções dos envolvidos, as dificuldades encontradas, as resoluções de problemas, a interação entre os licenciados e com o professor do ensino básico, etc. Os relatos dos licenciandos apontam, mesmo com a situação pouco favorável encontrada na escola, que é possível fazer um ensino e aprendizagem diferente com o uso da Cartografia Escolar no ensino básico.

\section{CONSIDERAÇÕES FINAIS}

Ao longo do texto busquei retratar algumas perspectivas da Cartografia na formação do professor de Geografia. Como já colocado no início do texto não se teve aqui a pretensão de esgotar cada dimensão apresentada em suas especificidades, nem mesmo o intuito de abarcar todas as multiplicidades existentes. 
Pode-se afirmar que discutir a Cartografia na formação do professor de Geografia nos dias atuais tornou-se um desafio muito grande, pois ela se apresenta multidimensional e, sem dúvidas alguma, cada uma tem a contribuir com o ensino de Geografia, principalmente a torna-lo mais dinâmico e inserido na realidade dos docentes e discentes do ensino básico.

\section{REFERÊNCIAS BIBLIOGRÁFICAS}

ACSELRAD, H; COLI, L. R. Disputas territoriais e disputas cartográficas. In: ACSELRAD, $\mathrm{H}$ (Org). Cartografias sociais e território. Rio de Janeiro: IPPUR/UFRJ, 2008.

ALMEIDA, R. A. Ensino de cartografia para populações Minoritárias. Boletim Paulista de Geografia, São Paulo, nº 87, p. 111-129, 2007.

ALMEIDA, R. D. Do desenho ao mapa: iniciação cartográfica na escola. São Paulo: Contexto, 2001.

Cartografia escolar. São Paulo: Contexto, 2007.

Novos rumos da cartografia escolar: currículo, linguagem e tecnologia. São Paulo: Contexto, 2011.

ALMEIDA, R. D; ALMEIDA, R. A. Fundamentos e perspectivas da cartografia escolar no Brasil. Revista Brasileira de Cartografia, Rio de Janeiro, N. 63/4, p. 885-897, Jul/Ago/2014.

ARSAC, L. L'evolution d'une théorie en didactique: l'exemple de la transposition didactique. Recherches en didactique des mathématiques, Genoble, Editions La Pensée Sauvage, v. 12, n. 1. p, 7-32, 1992.

BOLIGIAN, L; ALMEIDA, R. D. A Cartografia nos livros didáticos no período de 1824 a 1936 e a História da Geografia escolar no Brasil. In: ALMEIDA, R. D. Novos rumos da cartografia escolar: currículo, linguagem e tecnologia. São Paulo: Contexto, 2011

CANTO, T. S; ALMEIDA, R. D. Mapas feitos por não Cartógrafos e a prática cartográfica no ciberespaço. In: ALMEIDA, R. D. Novos rumos da cartografia escolar: currículo, linguagem e tecnologia. São Paulo: Contexto, 2011.

CASTRO, J. F. M. Geoprocessamento de mapas de Minas Gerais nos séculos XVIII - XIX. Belo Horizonte: Editora PUC Minas, 2017.

CHEVALLARD, Y. La transposition didactique. Grenoble: La Pensé Sauvave Editions, 1991.

DI MAIO, A. C. Geotecnologias digitais no ensino médio: avaliação prática de seu potencial, 2004, 171f. Tese (Doutorado em Geografia) - Universidade Estadual Paulista, Rio Claro, 2004. 
GEODEN: geotecnologias digitais no ensino básico por meio da Internet. In: Anais XIII Simpósio Brasileiro de Sensoriamento Remoto, Florianópolis, Brasil, 2126 abril 2007, INPE, p. 1457-1464.

FLORENZANO, T. G. Geotecnologias na Geografia aplicada: difusão e acesso. Revista do Departamento de Geografia, 17 (2005) 24-29.

FREISLEBEN, A. P; KAERCHER, N. A. Como usar de forma criativa o Google Earth, Maps, street view e desenhos manuais de mapas nas aulas de cartografia. Para Onde!?, 8 (2): 147-153, ago./dez. 2014.

GIRARDI, G. Cartografia geográfica: considerações críticas e proposta para ressignificação de práticas cartográficas na formação do profissional em Geografia, 2003, 191f. Tese (Doutorado em Geografia) - Universidade de São Paulo, 2003.

. Cartografia geográfica: reflexões e Contribuições. Boletim Paulista de Geografia, São Paulo, nº 87, p. 45-65, 2007.

. Apontamentos para uma cartografia da cartografia geográfica brasileira. Revista da ANPEGE, v. 7, n. 1, número especial, p. 237-250, out. 2011.

GONÇALVES, A. R et al. Analisando o uso de imagens do "Google Earth" e de mapas no ensino de Geografia. Ar@cne. Revista Electrónica de Recursos em Internet Sobre Geografía y Ciencias Sociales. Universidad de Barcelona, n.97, 1 de junio de 2007.

HARLEY, B. Mapas, saber e poder. Confins [Online], 5 | 2009, posto online em 24 abril 2009. Disponível em: < http://confins.revues.org/index5724.html> Acesso em 20 de nov. 2017.

IBGE. Sistema IBGE de Recuperação Automática- SIDRA. Disponível em < https://sidra.ibge.gov.br/home/ipca15/brasil> Acesso em 19 de nov. 2017.

KATUTA, A. M. A(S) Natureza da Cartografia. In: SEEMANN, J. A aventura Cartográfica: Perspectivas, pesquisas e reflexões sobre a Cartografia Humana. Fortaleza: Expressão Gráfica e Editora, 2005.

KOZEL, S. Comunicando e representando: mapas como construções socioculturais. In: SEEMANN, J. A aventura Cartográfica: Perspectivas, pesquisas e reflexões sobre a Cartografia Humana. Fortaleza: Expressão Gráfica e Editora, 2005.

MACEACHREN, A. M; TAYLOR, D. R. Visualization. Modern Cartography. Oxford, UK: Pergamon, 1994.

MAIA, D. C (Org). Ensino de Geografia em debate. Salvador: EDUFBA, 2014.

MELO, I. B. N. Proposição de uma Cartografia Escolar no Ensino Superior. 2007. Tese (Doutorado) - Rio Claro. Universidade Estadual Paulista, Rio Claro, 2007. 
. A Cartografia escolar no curso de Licenciatura em Geografia. In: MAIA, D. C (Org). Ensino de Geografia em debate. Salvador: EDUFBA, 2014.

OLIVEIRA, L. Estudo metodológico e Cognitivo do mapa, 1977, Tese (Livre Docência)-Universidade Estadual Paulista, Rio Claro, 1977.

.Estudo Metodológico e cognitivo do mapa. In: ALMEIDA, R. D. Cartografia escolar. São Paulo: Contexto, 2007.

RAISZ, E. Cartografia. Barcelona: OMEGA, 1985.

RAMOS, C. S. Visualização cartográfica e cartografia multimídia: conceitos e tecnologias. São Paulo: Editora UNESP, 2005.

ROSA, R. Geotecnologias na Geografia aplicada. Revista do Departamento de Geografia, 16 (2005) 81-90.

ROSA, R. U; SANTOS JÚNIOR, D. N; LAHM, R. A. O recurso das imagens de satélite para o estudo do lugar do educando: uma experiência na área da Matemática e da Geografia. Experiências em Ensino de Ciências - V2(2), pp. 2336, 2007.

SEEMANN, J. A aventura Cartográfica: Perspectivas, pesquisas e reflexões sobre a Cartografia Humana. Fortaleza: Expressão Gráfica e Editora, 2005.

Subvertendo a cartografia escolar no Brasil. Revista Geografares, $\mathrm{n}^{\circ} 12$, p.138-174, Julho, 2012

SILVA. A. P.A; CHAVES, J. M.Utilização do Google Maps e Google Earth no ensino médio: estudo de caso no Colégio Estadual da Polícia Militar-Diva Portela em Feira de Santana-BA. In: Anais XV Simpósio Brasileiro de Sensoriamento Remoto SBSR, Curitiba, PR, Brasil, 30 de abril a 05 de maio de 2011, INPE p.3220.

SIMIELLI, M. E. R. O mapa como meio de comunicação: implicações no ensino da geografia do $1^{\circ}$ grau, 1986, 205f. Tese (Doutorado em Geografia) - Universidade de São Paulo, São Paulo, 1986.

.Cartografia no ensino fundamental e médio. In: CARLOS, A. F. A. A

Geografia na sala de aula. São Paulo: Contexto, 2003.

SPÓSITO, M. E. As diferentes propostas curriculares e o livro didático. In: PONTUSCHKA, N. N.; OLIVEIRA, A. U. (Org.). Geografia em perspectiva. São Paulo: Contexto, 2002. p. 297-311. 